\title{
Sobre o Campo de Estudo da Memória Social: Uma Perspectiva Psicossocial
}

\author{
On the Study Field of Social Memory: A Psychosocial Perspective
}

Celso Pereira de Sá*

Universidade do Estado do Rio de Janeiro, Rio de Janeiro, Brasil

\begin{abstract}
Resumo
O artigo propõe uma circunscrição conceitual do campo da memória social segundo uma perspectiva psicossocial. Em primeiro lugar, definem-se cinco princípios unificadores básicos do campo da memória social na forma como se propõe que o psicólogo social o veja. Em segundo lugar, reforça-se tal unidade, tomando-se a expressão "memória social" para designar o inteiro conjunto de fenômenos psicossociais da "memória na sociedade". Em terceiro lugar, proporciona-se um mapeamento do campo nas sete instâncias da memória social com as quais se acredita que caiba ao psicólogo social lidar.

Palavras-chave: Memória social; psicologia social da memória; memória coletiva.
\end{abstract}

\begin{abstract}
The article proposes a conceptual circumscription of the field of social memory according to a psychosocial perspective. Firstly, one defined five basic unifying principles of the field of social memory in the manner that a social psychologist is proposed to see it. Secondly, such an unity is reinforced, by taking the expression "social memory" to designate the whole set of psychosocial phenomena of "memory in society". Thirdly, it is provided a mapping of the field in the seven instances of social memory with which it is believed that a social psychologist should deal.

Keywords: Social memory; social psychology of memory; collective memory.
\end{abstract}

A memória tem sido tema intensamente explorado pela filosofia e hoje é um conceito maior das ciências da cognição, das neurociências e da informática. A rigor, a memória tem sido apropriada como objeto de estudo não só para dar conta do funcionamento de organismos vivos e de máquinas, mas também da sociedade, da história, da cultura, da arte, da política e da literatura. Na psicologia, tem alimentado a pesquisa experimental de processos básicos, a teoria psicanalítica, a psicologia discursiva e os estudos cognitivos de caráter naturalista. Finalmente, o interesse pela memória invade hoje a vida cotidiana de uma maneira talvez nunca vista antes, como têm já diagnosticado diversos autores.

Embora a Psicologia Social já tenha ensejado uma investigação pioneira da memória no microcosmo social da vida cotidiana, com F. C. Bartlett, nos anos 30, somente há pouco mais de uma década esta disciplina aliou-se ao bloco das ciências humanas que - a rigor, não muito tempo antes - retomara esse estudo. A quantidade e diversidade de perspectivas teórico-conceituais - recuperadas e emergentes contribuem para aumentar cada vez mais a complexidade desse domínio acadêmico. É dentro de um tal quadro multifenomênico e multidisciplinar que o desafio do estudo da memória é enfrentado pela psicologia social.

\footnotetext{
* Endereço para correspondência: Rua General Ribeiro da Costa, 178, Bl. 1 , apto. 1201, Rio de Janeiro, RJ,22010-050. E-mail: sa.celso@gmail.com
}

Moscovici (1976) já mostrou o caminho para tal enfrentamento, no domínio do pensamento social. Antes de tudo, não há que permanecer apenas na psicologia, mas buscar formulações conceituais e teóricas relevantes onde quer que elas se encontrem. Se, como não é incomum, pelos níveis de análise e vieses próprios das diferentes disciplinas, tais formulações não dêem conta da inteira natureza psicossocial do fenômeno, cumpre aos psicólogos sociais reconstruir o estudo nos seus próprios termos.

É nesse sentido que, a partir do exame de diferentes formulações - de variadas origens e níveis de análise sobre a memória e construções afins, selecionadas por sua especial pertinência para a reconstrução psicossocial, propõe-se a presente circunscrição conceitual do domínio da memória social.

Tal proposta envolve três preocupações principais. Em primeiro lugar, arrolam-se cinco princípios unificadores básicos do campo da memória social, da forma como se propõe que um psicólogo social o veja. Em segundo lugar, busca-se reforçar tal unidade, tomando-se a expressão "memória social" para designar o inteiro conjunto de fenômenos psicossociais da "memória na sociedade". Em terceiro lugar, sugerem-se sete principais instâncias, as quais, sem serem mutuamente excludentes, constituem um mapeamento inicial das ênfases que podem se apresentar nos estudos da memória aos quais o psicólogo social se dedica. 


\section{Os Princípios Unificadores do Campo da Memória Social}

Não obstante seu caráter complexo e multifacetado, o campo de estudo da memória social parece ter recebido dos seus pioneiros - M. Halbwachs e F. C. Bartlett - uma influência unificadora básica, que guarda até hoje. Trata-se da proposição comum de que a memória humana não é uma reprodução das experiências passadas, e sim uma construção, que se faz a partir daquelas, por certo, mas em função da realidade presente e com o apoio de recursos proporcionados pela sociedade e pela cultura. O primeiro princípio a ser aqui arrolado é, pois, o caráter construtivo da memória social.

Os "quadros sociais da memória”, em Halbwachs (1925/1994), e a "convencionalização social”, em Bartlett (1932/1995), regem as respectivas preocupações construtivistas. De fato, ambos os autores, nessas e em outras proposições, demonstram consistentemente o caráter não meramente reprodutivo da memória e a influência das necessidades e interesses presentes na reconstrução do passado pela memória.

Trata-se provavelmente da principal influência unificadora do campo, que abriga a maioria das contribuições contemporâneas, independentemente de suas origens disciplinares. Ao adotá-la, a psicologia social da memória exclui do seu domínio apenas as perspectivas psicologistas segundo as quais as experiências permanecem intactas na memória dos indivíduos, podendo ser, com maior ou menor dificuldade, por eles reproduzidas.

O segundo princípio, por seu turno, exclui da perspectiva psicossocial as concepções sociologistas que tomam a memória como um atributo da sociedade ou dos grupos sociais. Trata-se da proposição de que, em última análise, são as pessoas que se lembram, embora a forma e boa parte do conteúdo das suas memórias sejam socialmente determinadas, pelos grupos, pelas instituições, pelos marcos mais amplos da sociedade, por recursos culturalmente produzidos, dentre os quais se inclui a própria linguagem.

A atribuição da memória aos grupos, às instituições e à sociedade se deve ao fato dela ter passado por uma progressiva exteriorização, através da invenção dos calendários, do desenvolvimento de uma "arte da memória", do advento da escrita, da imprensa, da fotografia, do computador, etc., como já convincentemente historiado por Le Goff(1996), dentre outros. Assim, ao mesmo tempo em que a memória deixava de ser considerada como um fenômeno exclusivamente psicológico, passava a ser retratada como tendo sua sede em instâncias de ordem sócio-cultural. Na circunscrição psicossocial ora proposta, a primeira mudança é vista como salutar, mas a segunda não é pertinente.

De fato, se outras abordagens disciplinares precisam dotar os seus conceitos-chave de um atributo de ordem psicológica, no mínimo como um recurso lingüístico econômico, o psicólogo social simplesmente não precisa deixar de considerar que são as pessoas que se lembram, para dar conta dos processos pelos quais a memória é tributária da sociedade, da história e da cultura. E é fazendo isso que ele pode talvez dar sua melhor contribuição ao campo da memória social.
O terceiro princípio sustenta que a construção, a manutenção e a atualização da memória social, mesmo em suas manifestações mais pessoais, estão na dependência da interação e da comunicação sociais. E isto em um tal grau que já foi sugerido (Connerton, 1993) que muito do que Halbwachs chamava de memória coletiva poderia ser explicado em termos de fenômenos de comunicação.

Também nas releituras de Halbwachs por Jedlowski (2000) e por Fentress e Wickham (1994), o princípio unificador da construção social da memória implica uma consideração explícita da interação e da comunicação como processos construtores. Embora seu peso possa variar de um máximo, como nas aproximações da psicologia discursiva (Middleton \& Edwards, 1994) e da teoria das representações sociais (Haas \& Jodelet, 1999; Jodelet, 1992), a uma simples incorporação tácita, ele perpassa a maioria das perspectivas atuais.

Algo que torna esse princípio de interesse especial para a abordagem psicossocial aqui defendida, é que são tais interação e comunicação - intra e/ou intergrupal, erudita e/ou de massa - que, pelo seu caráter atual, dão fundamento à tese da reconstrução do passado em função das necessidades e interesses do presente.

O quarto princípio, bastante associado ao anterior, propõe que memória e pensamento sociais estão intrinsecamente associados e são praticamente indistinguíveis, ou seja, o que é lembrado do passado está sempre mesclado com aquilo que se sabe sobre ele. De fato, como já argumentado por Halbwachs, o mero conhecimento de que certos fatos aconteceram - ou a conclusão lógica de que eles têm de ter acontecido -, mesmo se nenhuma lembrança foi guardada deles, é suficiente para sua incorporação à memória.

$\mathrm{O}$ que os quadros sociais identificados por Halbwachs e a convencionalização estudada por Bartlett proporcionam ao processo de construção social da memória é sempre uma forma de conhecimento: de fatos, de cronologias, de instituições, de costumes, de leis, da linguagem, ou seja, toda uma gama de recursos de contextualização e significação das experiências pessoais e grupais.

Num sentido complementar, observa-se a ocorrência de memórias no pensamento do tipo "representações sociais", através da ancoragem de experiências novas em conhecimentos preexistentes, o que já levou Moscovici (1976) a declarar que no conhecimento social o passado freqüentemente prevalece sobre o presente e a memória sobre a dedução. Além disso, a abordagem estrutural das representações sociais (Abric, 1994) propõe que a história do grupo e sua memória coletiva desempenham papel importante na constituição do sistema central de uma representação.

A distinção, segundo Tulving (1972), entre uma memória episódica - de fatos vividos - e uma memória semântica - de conhecimentos adquiridos - não tem aqui maior utilidade. $\mathrm{E}$ permanecem, mais uma vez, fora do campo da memória social as perspectivas psicologistas segundo as quais os registros das experiências vividas nunca são perdidos e, portanto, outros conteúdos cognitivos que lhes sejam acrescentados 
posteriormente ou que possam alterar os registros iniciais devem ser distinguidos da memória propriamente dita.

O quinto princípio retoma uma outra proposição comum a Halbwachs e a Bartlett, a de que o interesse - uma variável de ordem motivacional - e o sentimento desempenham um papel no processo construtivo da memória social. Em ambas as perspectivas, a emergência de novos interesses e a acentuação circunstancial de diferentes sentimentos são grandemente responsáveis pelo conteúdo que a memória social exibe em um ou outro momento e em um ou outro lugar.

Não se trata de, nesta última postulação, recuperar para os processos psicológicos algo como uma hegemonia no campo dos fenômenos da memória social, mas sim de sustentar que uma explicação psicossocial para a inequívoca determinação sócio-cultural da memória envolve a consideração não apenas de processos de construção sociocognitiva da realidade, mas também de modelação de interesses - uma variável de cunho nitidamente afetivo - e sentimentos em um dado conjunto social.

Além disso, a consideração das emoções e sentimentos como tem sido feito, por exemplo, por Jodelet (1992), De Rosa (2005), Rimé e Christophe (1998) - encontra uma grande ressonância em intelectuais não cientistas e pessoas comuns que, nas sociedades contemporâneas, cada vez mais se interessam pelo "mundo da memória", como o atestam, por exemplo, a produção e o consumo acentuados de películas cinematográficas, nas quais as vicissitudes da memória são sistematicamente associadas a dramáticas experiências afetivas. A esse propósito, estando já suficientemente demonstrado que o estudo científico de um fenômeno não independe inteiramente das representações que ele assume na sociedade mais ampla, cabe especular que talvez os estudos sobre a memória social não tivessem sido retomados com tanta intensidade se não estivessem respondendo a uma demanda implícita da sociedade.

\section{A Memória Social e suas Variadas Instâncias}

A memória pode ser vista como um conceito, oriundo de uma antiga psicologia filosófica, que se expandiu de modo a abarcar uma quantidade de fenômenos ou mesmo de temáticas ou hipóteses de trabalho científico. Nesse sentido, numerosos envolvimentos acadêmicos, bem como as incursões leigas sobre o assunto, têm produzido uma rica e diversificada adjetivação dos fenômenos ou manifestações da memória em sociedade.

Distinções entre tais manifestações têm sido propostas por alguns autores, dentre as quais destaca-se a que Jedlowski (2000, 2001, 2005) faz entre memória coletiva, memórias comuns, memória social e memória pública. Essa sistematização foi tomada como base para o mapeamento a ser apresentado nesta seção e que contempla distinções conceituais básicas, mas busca ainda lhes associar categorizações temáticas da memória engendradas ao longo do seu estudo empírico.

Uma das diferenças que o presente mapeamento guarda em relação à classificação de Jedlowski é que optou-se por designar como "memória social" o inteiro conjunto dos fenômenos ou instâncias sociais da memória. Essa decisão de conferir um caráter "guarda-chuva" exclusivo ao termo "memória social" se justifica nos termos que se seguem.

Em primeiro lugar, acredita-se que, se um domínio de fenômenos - ou de estudos - existe de fato, é conveniente que ele possa ser identificado por uma designação genérica e abrangente. Na perspectiva psicossocial aqui eleita, a adjetivação "social" parece ser a mais adequada, embora, para isso, se deva destituir o termo de sua caracterização sociológica como uma "memória da sociedade", a qual, a rigor, já é grandemente - se não inteiramente - contemplada pelas variadas noções de acervo e de patrimônio - cultural e histórico, material e imaterial.

Em segundo lugar, de uma forma espontânea, o termo já vem recebendo essa preferência aglutinadora na literatura sobre a "memória na sociedade", quando mais não seja por uma questão de economia verbal, sempre que não se tem querido ou precisado especificar um domínio próprio de mobilização ou circunstâncias específicas de produção, transmissão e esquecimento.

Assim, segundo a presente proposta, quando se fala em memória social pode-se estar falando de muitas coisas, não necessariamente muito diferentes entre si, mas distinguíveis em função de variados critérios, como se vê nas memórias $d a$ memória social (Sá, 2005) que se seguem.

Memórias pessoais. O termo "memórias pessoais" é aqui tomado por empréstimo de Connerton (1993), que o usa para designar "aqueles atos de recordação que tomam como objeto a história de vida de cada um . ..., que se localizam num passado pessoal e a ele se referem" (p. 26).

As memórias pessoais não são concebidas como tendo uma origem e um funcionamento estritamente individuais, mas sim como resultado de um processo de construção social. São, assim, memórias sociais, embora o locus desse processo construtivo seja a pessoa, pois é ao passado dela que estão continuamente referidas as lembranças, mesmo que envolvam também fatos sociais, culturais ou históricos de que ela tenha participado, testemunhado ou simplesmente ouvido falar.

A preferência pelo termo "pessoais", em lugar de "individuais”, se deve a que nele próprio já está embutida uma dimensão social. De fato, na literatura corrente em psicologia social, a referência à "pessoa" implica reconhecê-la como produto de processos de socialização, como ocupando posições e desempenhando papéis sociais, como dotada de uma identidade construída através da interação social e como reflexivamente consciente desta. São essas mesmas condições sociais da constituição e funcionamento das pessoas que se encontram presentes na construção, reconstrução e atualização das suas memórias.

Em termos de pesquisa empírica, as memórias pessoais são estudadas sob o rótulo de memórias autobiográficas. Incluem-se aí as histórias de vida, que supõem um esforço de reconstrução global e tão completo quanto possível da memória pessoal, mas também a recuperação de episódios específicos, a qual, para distinguir das primeiras, já foi chamada de recollective memory (Brewer, 1999). 
Memórias comuns. Esta categoria, tomada de Jedlowski (2000), designa as lembranças que são comuns a conjuntos mais ou menos amplos de pessoas que não se mantém necessariamente em interação e que, portanto, não chegam a discuti-las ou a elaborá-las coletivamente.

As memórias comuns podem ser vistas como coleções de muitas memórias pessoais acerca de um mesmo objeto, construídas independentemente umas das outras. Por força de sua participação comum em dado período histórico, em dada configuração cultural ou em dado estrato social, tais pessoas teriam sido expostas aos mesmos fatos, às mesmas informações, aos mesmos gostos, etc., e deles guardariam aproximadamente as mesmas lembranças.

O conceito pode ser útil no estudo de diversos fenômenos, como as memórias geracionais, as quais são balizadas por eventos históricos, mudanças sociais e preferências culturais que podem ter sido objeto de elaboração por certos grupos - os quais podem ter sido inclusive seus principais protagonistas -, mas não necessariamente por toda uma coorte geracional. Não obstante, acabam por ser apropriadas, como memórias comuns, por praticamente todos os participantes da geração e conferem ao inteiro conjunto uma identidade característica e única (Conway, 1998; Mannheim, 1982).

Como argumenta Jedlowski (2005), os meios de comunicação de massa têm sido responsáveis por uma crescente ampliação e homogeneização das memórias, a ponto de deixar pouca margem para a elaboração propriamente coletiva. Na medida em que as memórias comuns passam a constituir uma porção cada vez mais significativa da memória social nas sociedades contemporâneas, a importância do seu estudo aumenta na mesma proporção. Ou seja, mais do que atender à exigência lógica de suprir uma lacuna conceitual entre as memórias pessoais e as coletivas, a construção e o funcionamento das memórias comuns passam a se impor como problema substancial de pesquisa.

Memórias coletivas. O conceito tradicional de memórias coletivas, cunhado por Halbwachs (1950/2004), é aqui mantido para designar as memórias que, em seu processo de construção, são objeto de discursos e práticas coletivas por parte de grupos sociais razoavelmente bem definidos. Em sua atualização do pensamento de Halbwachs, Jedlowski (2001) define a memória coletiva como "um conjunto de representações sociais acerca do passado que cada grupo produz, institucionaliza, guarda e transmite através da interação de seus membros" (p. 33).

Três quartos de século depois de proposto, o conceito se defronta com dificuldades geradas pelas transformações da sociedade desde então. Em primeiro lugar, as delimitações grupais foram se tornando cada vez mais imprecisas e obrigando assim à sua consideração em termos latos e flexíveis. Em segundo lugar, a influência unidirecional e acabada dos meios de comunicação de massa vem crescentemente tomando o lugar da comunicação e da negociação intragrupais. Em terceiro lugar, a interação face a face, comumente evocada quando se pensa numa elaboração coletiva ou propriamente grupal, está sendo rapidamente substituída pela interação via internet.
Não obstante, a referência à memória nos limites de um grupo - que tem um começo histórico, do qual nem todos os membros participam com a mesma intensidade, em relação ao qual as pessoas podem ingressar ou sair, que pode sofrer transformações e até acabar - continua a proporcionar um recurso teórico bastante conveniente para explicar a formação, a manutenção e o eventual desaparecimento de memórias coletivas. Além disso, estas constituem a matéria prima geral - ou, às vezes, unidades identificáveis - de algumas das demais instâncias da memória social que serão examinadas a seguir.

Plenamente descartável pela perspectiva psicossocial é apenas a proposição halbwachiana original de que a memória coletiva é uma memória do grupo, autônoma em relação aos seus membros, e de que as memórias pessoais - e as comuns - seriam fundamentalmente dependentes dela. De qualquer forma, descontando as dificuldades do conceito face à permeabilidade crescente da vida em sociedade e à sua penetração pela mídia, constituem ainda focos adequados de estudo, em termos de memórias coletivas, variadas memórias grupais específicas (de famílias, de associações, de grupos de pares, etc.).

Memórias históricas documentais. Pela designação de "memória histórica” busca-se explorar a complexa interface da memória com a história. A própria expressão memória histórica já foi objeto de um veto terminológico por parte de Halbwachs, que a considerava como uma contradição em termos, visto que a história começaria a ser escrita exatamente quando a memória estivesse se extinguindo. $\mathrm{O}$ campo da memória social, entretanto, se expandiu além dos limites autorizados por esse pioneiro e nada obsta a que, a par de uma "história da memória” (Le Goff, 1996), se possa falar hoje em dia de uma "memória da história”, em duas modalidades - documentais e orais.

A categoria das "memórias históricas documentais" é proposta para dar conta daquilo que Jedlowski chama de "memória social” e que consistiria nos mais variados registros e traços do passado - documentos, em sentido amplo - que se encontram virtualmente disponíveis a qualquer membro de uma dada sociedade, em museus e em bibliotecas, sob a forma de monumentos públicos, de manifestações culturais diversas, e assim por diante. $\mathrm{Na}$ presente perspectiva psicossocial, entretanto, os documentos não se configuram, pela mera disponibilidade, como uma memória, cabendo falar de memória histórica somente quando tais documentos são de fato mobilizados - efetivamente lidos, utilizados, visitados, apreciados ou ainda simplesmente referidos - por pessoas e grupos sociais contemporâneos.

Esse critério de "mobilização documental" é admitidamente pouco preciso, como já observou Candau (1998), mas, por isso mesmo, pode dar conta da flutuação característica dos fenômenos psicossociais. Por exemplo, os arquivos da ditadura militar brasileira, que se constituíram como documentos ao longo de vinte anos (1964-1985), estão passando hoje, na iminência e na polêmica de sua abertura, à condição de memória. Uma importante noção que vem em apoio ao critério é a dos lugares de memória (Nora, 
1997), em que os documentos podem se tornar quando é socialmente investida sobre eles uma "vontade de memória”, pois, na ausência desta, eles permaneceriam como "lugares de história”.

São ainda fontes para essa subcategoria duas espécies de recursos de uso mais amplamente socializado: (a) os manuais escolares de história; (b) os registros proporcionados pela comunicação de massa. Os dois têm sido grandemente responsáveis pela transformação de fatos não vividos em memórias comuns, notadamente geracionais, e coletivas. Uma ilustração dessa forma de construção social da memória histórica é dada por uma pesquisa sobre a memória social do descobrimento do Brasil, por ocasião do seu quinto centenário (Sá \& Castro, 2005), que buscou, dentre outras coisas, investigar o papel das imprensas e dos manuais escolares brasileiros e portugueses na atualização daquela memória.

Memórias históricas orais. Esta modalidade de memória histórica faz interface com a história que não foi escrita ou que apenas recentemente passou a ser transcrita, a chamada história oral. Dizendo de outra maneira, a categoria engloba os fenômenos de memória social que constituem as fontes não documentais com que lida a história oral. Trata-se de uma "memória da história" que, por não contar com documentos sobre os quais se apoiar ou por repudiar aqueles porventura existentes, vale-se apenas de recursos “internos" - no sentido de uma memória não exteriorizada em suportes materiais -, como a rememoração e a transmissão orais.

Embora a fronteira entre memória e história seja aqui muito tênue, a distinção é importante, pois a preocupação do psicólogo social não é com a preservação dos relatos ou com a confiabilidade das fontes, como faz a história oral, mas sim com o processo e com as circunstâncias segundo os quais tais memórias são construídas, reconstruídas ou atualizadas por conjuntos sociais mais ou menos amplos e, por diferentes critérios, suficientemente circunscritos. Este é o terreno em que talvez a psicologia social possa mais aprender sobre a construção de memórias coletivas e, dessa aprendizagem, recortar subsídios críticos úteis para a prática da história oral.

Os estudos no âmbito desta instância, que têm recebido os variados rótulos de memórias nacionais, étnicas, comunitárias, etc., aplicaram-se originalmente aos povos sem escrita, mas hoje se intensificam com relação àqueles que, tendo sido por muito tempo dominados, recentemente recuperaram sua autonomia.

Memórias práticas. Até aqui, o sistema classificatório privilegiou como suportes da memória - quando não como sua própria essência - os discursos ou narrativas, em forma escrita ou oral, e as imagens. A presente categoria visa completar o quadro, contemplando a memória implicada nas práticas sociais performativas, como demonstrada por Connerton (1993) e endossada por outros autores, dentre os quais Jedlowski (2000).

Connerton (1993) distingue entre “práticas de inscrição”, que correspondem aos recursos externos de armazenagem e recuperação da informação, e "práticas de incorporação", pelas quais a memória é acumulada e sedimentada no próprio corpo humano, manifestando-se através de rituais e de práticas corporais. Uma ilustração combinada dessas duas manifestações é dada pelo ato de ajoelhar na igreja católica, que integra uma memória religiosa fixada - não apenas na cultura, mas também no corpo de cada participante - de forma mais persistente e eficaz do que seria uma mera declaração verbal de submissão à divindade.

Esta instância da memória social distingue-se marcadamente das demais, tanto em termos de sua construção quanto de sua resistência a transformações em função de mudanças sociais. A transmissão dessa memória é feita, como observa Candau (1998), sem se pensar: "ela provém da imersão na sociedade desde a tenra infância mais do que de uma transmissão explícita” (p. 115). Daí decorre que "ela conserva, reitera e reproduz bem mais do que transforma, cria e reconstrói” (p. 115).

Essas memórias práticas provavelmente acompanham, em maior ou menor grau, o estofo discursivo, imagético e principalmente afetivo das demais instâncias e podem ter como campo privilegiado de estudo as memórias institucionais, comumente caracterizadas pela longa permanência ou mesmo pela inércia.

Memórias públicas. A expressão "memória pública”, que tem comportado diversas acepções, recebe de Jedlowski (2005) um significado extremamente relevante para a sociedade contemporânea, que convém tomar como uma categoria especial da memória social. Memória pública é, para esse autor, a memória da esfera pública, entendida esta como “o campo da vida nas modernas sociedades democráticas onde as crenças dos cidadãos acerca dos assuntos políticos são discutidas” (p. 93).

De fato, diz Jedlowski (2005), a discussão política não se faz sem referência constante ao passado e às representações sobre o passado, constituindo assim a arena onde memórias coletivas múltiplas se confrontam. A esfera pública é também onde mais nitidamente se observam as relações entre poder e memória, onde proliferam os chamados "usos públicos da história”, onde são esgrimidos os argumentos opostos do "dever de memória” e da "necessidade de esquecimento”, onde as memórias se encontram cada vez mais submetidas à mediação dos meios de comunicação de massa.

Uma noção que guarda grande afinidade com a de memórias públicas é a de memórias de massa, proposta por Jodelet (1992). Estas, pela sua emergência contemporânea como um fenômeno de massa, operam em uma escala social mais abrangente do que as memórias coletivas, que são produzidas e mobilizadas dentro de limites grupais estritos.

Segundo a autora, o processo construtivo dessas memórias tem estado voltado para "o desenvolvimento da responsabilidade coletiva e a mobilização em favor da defesa dos direitos humanos" (1992, p. 246), o que faz dela uma importante modalidade de memória pública. A constituição de uma tal memória de massa foi estudada por Jodelet no contexto do julgamento do carrasco nazista Klaus Barbie, em 1984, em Lyon, durante o qual memórias pessoais, comuns e coletivas, 
produzidas e mantidas regionalmente, foram compartilhadas, através da mídia, com o mundo inteiro.

\section{Conclusão}

Duas são as principais falhas que o mapeamento esboçado na segunda parte deste artigo apresentaria se tivesse a pretensão de constituir um sistema taxionômico. Em primeiro lugar, as categorias esboçadas não são mutuamente excludentes. Por exemplo, memórias históricas orais são memórias coletivas, memórias práticas podem estar presentes nas demais instâncias, várias destas podem compor as memórias públicas, e assim por diante. Além disso, como aponta Jedlowski, algumas instâncias podem se transformar em outras - memórias comuns em memórias coletivas, por exemplo - no curso dos processos psicossociais de reconstrução ou atualização da memória social. Por outro lado, o conjunto não se pretende exaustivo, razão pela qual ele deve se manter aberto à incorporação de novas categorias que designem consistentemente algum aspecto digno de aprofundamento no campo da memória social.

Um mérito que se pode atribuir às distinções propostas, em termos da pesquisa psicossocial, é o de orientar a seleção das abordagens teóricas e dos recursos metodológicos adequados na investigação de algum fenômeno concreto de memória social. Por exemplo, cabe utilizar explicações de ordem grupal, se se verificou que se trata de uma memória coletiva, mas não se o que está em jogo é uma memória comum. Ou, descrever uma memória histórica não apenas a partir do que se encontra registrado em documentos, mas também da forma como estes são apropriados por uma população contemporânea.

Acredita-se, por outro lado, que as memórias aqui resenhadas atendem todas aos requisitos unificadores do campo da memória social em uma perspectiva psicossocial, como definidos na primeira parte do artigo: seu caráter construtivo, sua natureza simultaneamente social e psicológica, sua dependência estreita da comunicação e da interação social, sua imbricação com o pensamento social, sua dinâmica afetiva. Cabe, entretanto, admitir que a presença de um ou outro desses requisitos possa não se mostrar, de início, muito evidente em uma ou outra das instâncias conceituais identificadas. Evidenciá-los, articulá-los e explorar suas implicações na pesquisa da memória social são algumas das tarefas da análise psicossocial.

\section{Referências}

Abric, J-C. (1994). Les représentations sociales: aspects théoriques. In J-C. Abric (Ed.), Pratiques sociales et représentations (pp. 11-35). Paris: Presses Universitaires de France.

Bartlett, F. C. (1995). Remembering: A study in experimental and social psychology. Cambridge, MA: Cambridge University Press. (Original publicado em 1932)

Brewer, W. F. (1999). What is recollective memory? In D. C. Rubin (Ed.), Remembering our past: Studies in autobiographical memory (pp. 19-66). Cambridge, MA: Cambridge University Press.

Candau, J. (1998). Mémoire et identité. Paris: Presses Universitaires de France.
Connerton, P. (1993). Como as sociedades recordam. Oeiras, Portugal: Celta.

Conway, M. A. (1998). El inventario de la experiencia: memoria e identidad. In D. Páez, J. F. Valencia, J. W. Pennebaker, B. Rimé \& D. Jodelet (Eds.), Memorias colectivas de procesos culturales y políticos (pp. 49-82). Bilbao, España: Universidad del País Vasco.

De Rosa, A. S. (2005) O impacto das imagens e do compartilhamento social das emoções na construção da memória social: Uma chocante memória "flash" de massa do 11 de setembro até a guerra do Iraque. In C. P. Sá (Ed.), Memória, imaginário e representações sociais (pp. 121-164). Rio de Janeiro, RJ: Editora do Museu da República.

Fentress, J., \& Wickham, C. (1994). Memória social. Lisboa, Portugal: Teorema.

Haas, V., \& Jodelet, D. (1999). Pensée et mémoire sociale. In J-P. Pétard (Ed.), Psychologie sociale (pp. 113-160). Rosny, France: Bréal.

Halbwachs, M. (1994). Les cadres sociaux de la mémoire. Paris: Albin Michel. (Original publicado em 1925)

Halbwachs, M. (2004). A memória coletiva. São Paulo, SP: Centauro. (Original publicado em 1950)

Jedlowski, P. (2000). La sociología y la memoria colectiva. In A. Rosa, G. Bellelli \& D. Bakhurst (Eds.), Memória colectiva e identidad nacional (pp. 123-134). Madrid, España: Biblioteca Nueva.

Jedlowski, P. (2001). Memory and sociology: Themes and issues. Time E' Society, 10(1), 29-44.

Jedlowski, P. (2005). Memória e mídia: Uma perspectiva sociológica. In C. P. Sá (Ed.), Memória, imaginário e representações sociais (pp. 87-98). Rio de Janeiro, RJ: Editora do Museu da República.

Jodelet, D. (1992). Mémoire de masse: le côté moral et affective de l'histoire. Bulletin de Psychologie, 45(405), 239-256.

Le Goff, J. (1996). História e memória. Campinas, SP: Editora da Universidade Estadual de Campinas.

Mannheim, K. (1982). O problema sociológico das gerações. In M. M. Foracchi (Ed.), Karl Mannheim (pp. 67-95). São Paulo, SP: Ática.

Middleton, D., \& Edwards, D. (Eds.). Collective remembering. London: Sage.

Moscovici, S. (1976). La psychanalyse, son image et son public. Paris: Presses Universitaires de France.

Nora, P. (1997). Entre mémoire et histoire: la problématique des lieux. In P. Nora (Ed.), Les lieux de mémoire (pp. 23-43). Paris: Gallimard.

Rimé, B., \& Christophe, V. (1998) Cómo los episodios emocionales individuales alimentan la memoria colectiva. In D. Páez, J. F. Valencia, J. W. Pennebaker, B. Rimé \& D. Jodelet (Eds.), Memorias colectivas de procesos culturales y políticos (pp. 151-170). Bilbao, España: Universidad del País Vasco.

Sá, C. P. (2005). As memórias da memória social. In C. P. Sá (Ed.), Memória, imaginário e representações sociais (pp. 63-86). Rio de Janeiro, RJ: Editora do Museu da República.

Sá, C. P., \& Castro, P. (Eds.). (2005). Memórias do descobrimento do Brasil. Rio de Janeiro, RJ: Editora do Museu da República.

Tulving, E. (1972). Episodic and semantic memory. In E. Tulving \& W. Donaldson (Eds.), Organization of memory (pp. 381-405). New York: Academic Press.

Recebido: 16/08/2006 $1^{a}$ revisão: 20/10/2006 Aceite final: 01/11/2006 